\title{
Piloting tele-monitoring in COPD: a mixed methods exploration of issues in design and implementation
}

\author{
Jenny Ure a , *Hilary Pinnockb, Janet Hanleya, Gillian Kiddc, Emily McCall Smith ${ }^{d}$, \\ Alex Tarling', Claudia Pagliaric, Aziz Sheikh'b, William MacNee e, Brian McKinstryc
}

a Midwifery and Social Care, Edinburgh Napier University School of Nursing, Edinburgh, UK

b Allergy and Respiratory Research Group, Centre for Population Health Sciences, The University of Edinburgh, Edinburgh, UK eHealth Research Group, Centre for Population Health Sciences, The University of Edinburgh, Edinburgh, UK

' The Royal Infirmary Edinburgh, Edinburgh, UK

Edinburgh Lung and the Environment Group Initiative, MRC Centre for Inflammation Research, The Queen's Medical Research Institute,

The University of Edinburgh, Edinburgh, UK

Received 13th November 2010; revised 6th February 2011; accepted 20th March 2011; online 22nd July 2011

\begin{abstract}
Background: In 2008 NHS Lothian implemented a COPD tele-monitoring service incorporating a touch-screen computer for daily recording of symptoms and weekly oximetry and spirometry measurement. Data were transmitted by secure broadband link to a call centre where trained workers monitored data and contacted clinicians according to an agreed algorithm.

Aims: To explore the perceptions of patients and professionals about the pilot implementation of the COPD tele-monitoring service.

Methods: In-depth interviews were undertaken with patients and professionals before and after installation of the tele-monitoring equipment. Interviews were recorded, transcribed and thematically analysed. Data on use of healthcare resources were obtained from primary care records.

Results: Twenty of the 27 patients in the pilot and 25 professionals participated. ( $n=55$ interviews and one focus group). Patients were generally positive about the technology, which they perceived enabled earlier recognition of exacerbations and facilitated access to clinical advice. In contrast, clinicians had concerns about false positive symptom scores, difficulties in interpreting physiological data, overtreatment (reflected in a large increase in antibiotics and steroid prescribing), and an increased workload.

Conclusions: Tele-monitoring was perceived by patients as improving access to professional care, but raised concerns for clinicians about possible over-treatment and how best to organise services to support the technology.

(c) 2012 Primary Care Respiratory Society UK. All rights reserved.

J Ure, et al. Prim Care Respir J 2012; 21(1): 57-64

http://dx.doi.org/10.4104/pcrj.2011.00065
\end{abstract}

Keywords COPD, exacerbation, primary care, qualitative, quantitative, Telehealth

See linked editorial by Cafazzo et al. on pg 10

The full version of this paper, with online Appendices,

is available at www.thepcrj.org

\section{Introduction}

Globally, healthcare systems are seeking cost-effective strategies for delivering sustainable care for populations with an increasing burden of long-term conditions. ${ }^{1}$ Key policies include shifting care into the community, ${ }^{2,3}$ promoting self-care, ${ }^{4-6}$ and seeking technological solutions. ${ }^{7,8}$
The theoretical model developed by Glasziou et al. describes the complementary and evolving roles of periodic professional reviews and ongoing patient self-monitoring. ${ }^{9}$ The context for tele-monitoring is the maintenance phase where patients are monitoring a relatively stable situation and may need to act (either by initiating treatment or seeking professional advice) if measurements fall outside predefined limits. Tele-monitoring operates at the boundary between self-care and professional care, ${ }^{10}$ providing professional support for self-monitoring and facilitating timely communication (Figure 1).

Despite the theoretical benefits of tele-monitoring systems,

\footnotetext{
* Corresponding author: Dr Hilary Pinnock, Centre for Population Health Sciences, University of Edinburgh, Doorway 3, Medical School, Teviot Place, Edinburgh, EH8 9DX, UK. Tel: +44 (0)1316508102 E-mail: hilary.pinnock@ed.ac.uk
} 
Figure 1. The chronic disease management pyramid showing the boundary between professional and selfcare (reproduced with permission from Kielmann et al. ${ }^{10}$ )

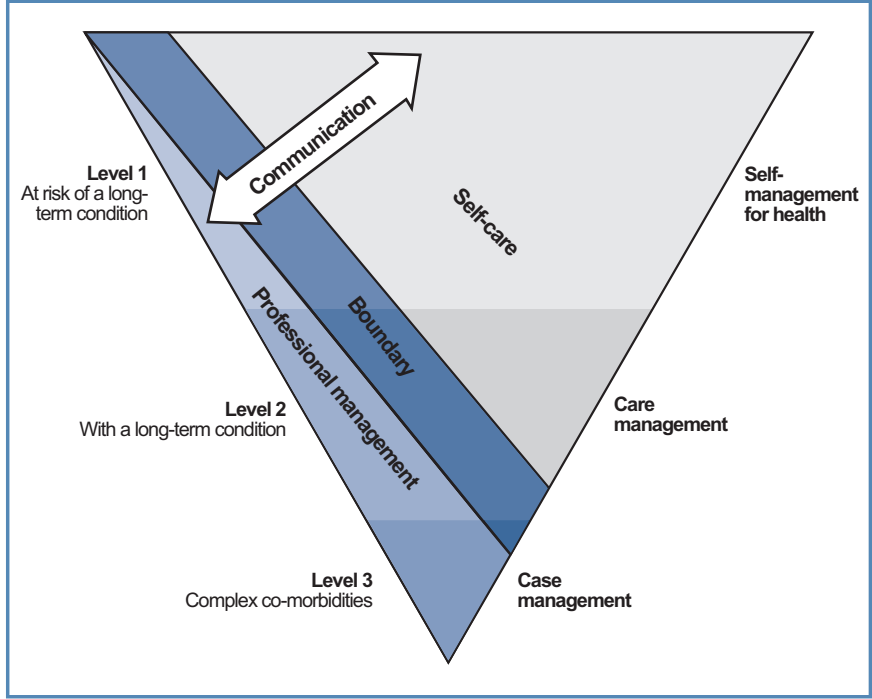

their effectiveness in improving outcomes for people with chronic obstructive pulmonary disease (COPD) has not yet been established. ${ }^{11}$ Small-scale pilot studies and service evaluations have demonstrated promising reductions in hospitalisations, ${ }^{12,13}$ but suggest that the impact of tele-monitoring is influenced by the clinical context in which it is implemented. ${ }^{14}$ Evaluating the clinical and cost-effectiveness of tele-monitoring systems for COPD has been identified as a research priority internationally, ${ }^{15}$ which the TELESCOT Programme aims to address within the UK. ${ }^{16}$

\section{The TELESCOT COPD tele-monitoring service} (Figure 2)

Patients used a touch-screen computer (Intel Corporation, Santa Clara, California, USA) to record a validated daily symptom score comprising questions which may suggest the onset of an exacerbation (Table 1) ${ }^{17}$ - for example, "I am more breathless than usual" or "My sputum has increased in amount". Physiological measurements including oxygen saturation and forced expiratory volume in 1s (FEV 1$)$ were taken with Bluetooth-linked monitoring devices. Data were transmitted via a dedicated broadband link to a call centre (West Lothian Community Alarm Services) manned by trained support staff who contacted the patient or their primary care practice according to an algorithm based on the questionnaire responses, or if no data were submitted (Figure 3). Patients were provided with an action plan and an emergency supply of antibiotics and steroids which they were encouraged to commence as soon as an exacerbation was recognised. Clinical care was provided by their usual primary care practice and the outof-hours service at weekends.

\section{Figure 2. The COPD tele-monitoring system}

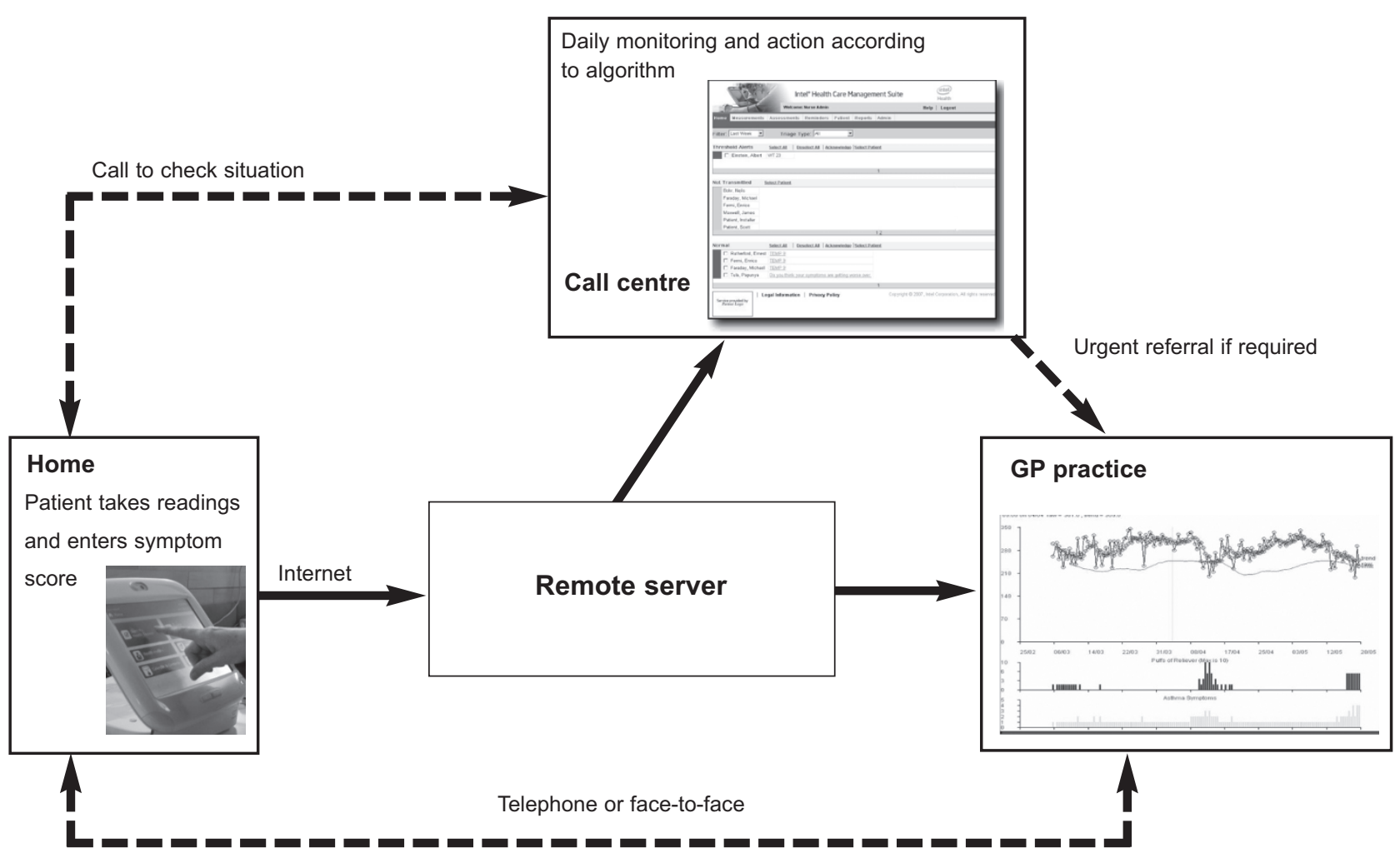

Consultation arranged as appropriate 


\begin{tabular}{l} 
Table 1. The daily symptom questionnaire \\
Each day, please record any WORSENING of symptoms from your usual \\
daily level. The symptoms we are interested in are listed below, just tick \\
yes or no in the box beside each symptom: \\
\hline Symptom: \\
I am more breathless than usual* \\
My sputum has increased in colour* \\
My sputum has increased in amount* \\
I have a cold (such as runny or blocked nose) \\
I have increased wheeze or chest tightness \\
I have a sore throat \\
I have an increased cough \\
I have a fever \\
\hline *These three core symptoms score two points. The other symptoms \\
score 1 point.
\end{tabular}

Figure 3. NHS Lothian Telehealth Project Call Centre algorithm

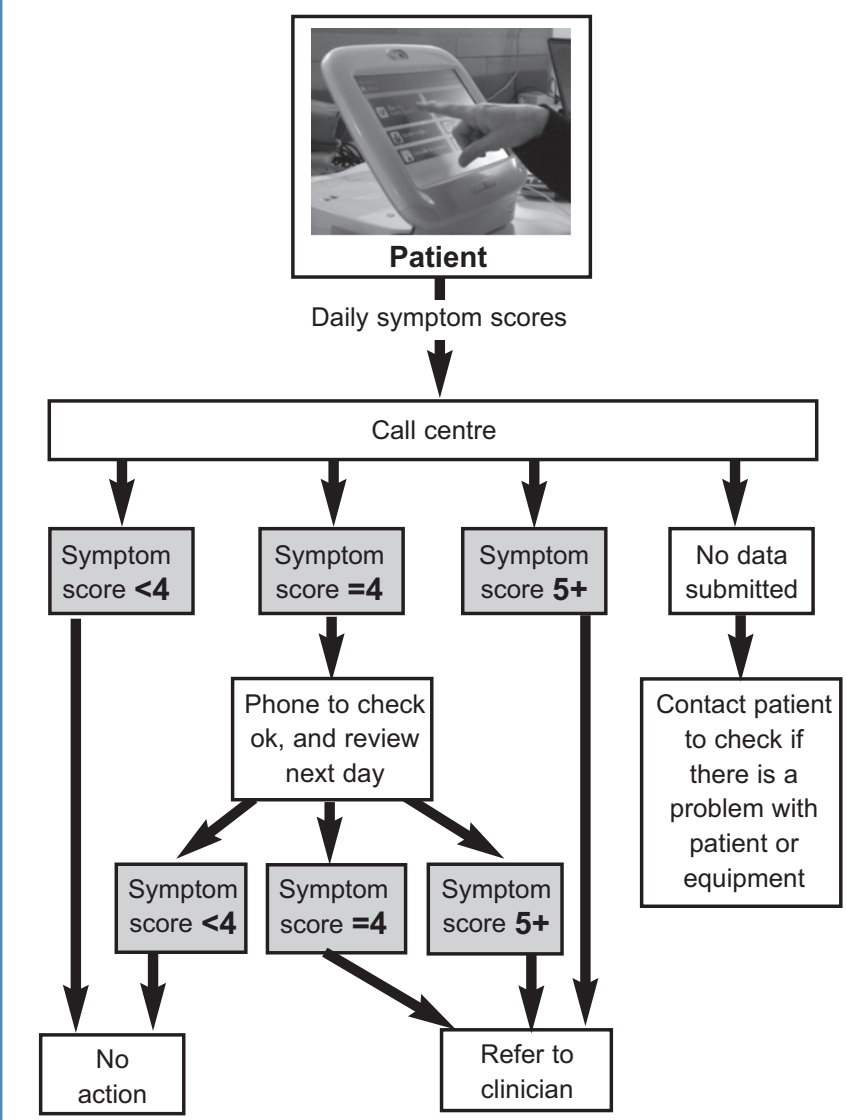

The symptoms score refer to the daily questionnaire (see Table 1)

\section{The TELESCOT Programme}

Set within the Medical Research Council Framework for the design and evaluation of complex interventions, ${ }^{18}$ the TELESCOT Programme is undertaking a multifaceted evaluation of a COPD tele-monitoring service provided by NHS Lothian, Scotland (http://www.telescot.org). We here report the results of a pilot study which aimed to inform the implementation of the service and the design of our proposed randomised controlled trial (RCT). ${ }^{19}$ Our specific objectives were to assess the acceptability of the system to patients and clinicians, the feasibility of the service provision, and an estimation of the potential impact on clinical outcomes.

\section{Methods}

The study took place in 2008 and included both qualitative and quantitative assessments. Ethics approval was obtained from the Lothian LREC 4 (07/S1104/45) and governance approval was obtained from NHS Lothian (2008/P/GP/04).

\section{Patient recruitment}

NHS Lothian deployed 27 tele-monitoring systems in the homes of patients selected as having moderate/severe COPD and at risk of a hospital admission from four participating practices situated in relatively deprived areas of Lothian (in keeping with the recognised demographic of (OPD). The only exclusion criterion was moderate/severe dementia. Patients were invited by letter from their GP to participate in the qualitative interviews and to allow collection of data from their primary care records.

\section{Qualitative data collection}

Interviews, focus groups, and ethnographic observations were conducted by $\mathrm{JU}$, an experienced qualitative researcher, with input from GK and AT.

\section{a) Patient interviews}

Patients were invited to provide two face-to-face semi-structured interviews, one before the equipment was installed to capture expectations and concerns about tele-monitoring, and a second interview after at least 2 months' experience of the service (see Appendix 1, available at www.thepcrj.org, for the topic guide). Interviews were conducted in the patients' homes, jointly with the carer as appropriate, and typically lasted around half an hour.

\section{b) Professional interviews and focus groups}

We used the complementary techniques of semi-structured interviews and focus groups to explore the perceptions of healthcare professionals and managers involved in the implementation of the tele-monitoring service or in providing clinical support for patients. We aimed to recruit a maximum variation sample encompassing people from a range of ages and both genders with varying views on tele-health. The interviews, which lasted approximately 30 minutes (face-to-face or by telephone according to the participants' preference), were undertaken at different time points in the set-up of the service and explored perceptions of the technology and service provision and the perceived barriers/facilitators to implementation. A 1-hr focus group of local community nurse managers involved in the implementation was held. All interviews and focus groups were audio-recorded with consent and transcribed verbatim.

\section{c) Ethnographic observations}

To provide context, the researchers (JU and AT) observed the installation process and utilisation of the equipment in a sample 
of households selected to ensure a range of age, gender, severity of COPD, and social circumstance (e.g. availability of a carer). Field notes focused on the practicalities of use in the home and of any difficulties associated with location and usage. Two planning meetings of clinical staff including nurse managers, community nurses and physiotherapists, were also observed and audio-recorded.

\section{Quantitative data collection}

Participating patients were visited by a research nurse who took informed consent, collected demographic details, and undertook a baseline assessment including the outcome measures that we planned to use in the RCT. ${ }^{19}$ All measures were repeated at the end of the 6-month pilot. The research nurse collected data about respiratory health service utilisation including primary care consultations, outpatient visits, admissions, and all drugs prescribed for COPD during the pilot period and for the corresponding six months in the previous year (in order to minimise seasonal effects).

\section{Data handling and analysis}

The qualitative data were entered into NVivo 7. Coding of all recordings and field notes was carried out and iteratively refined using paired analysis of transcripts by three researchers (JU, GK and AT) and in collaboration with the wider group to generate a table of themes and sub-themes with the associated text segments (see Appendix 2, available at www.thepcrj.org, for coding framework). Concurrent data analysis allowed emergent themes to be incorporated into the topic guide and explored in subsequent interviews and observations. Data generation continued until saturation was achieved. Deviant cases and possible conflicting interpretations were actively sought. We used the field notes from the ethnographic observations to add context to the process of installation and use within the home environment. We remained aware throughout that qualitative research is a reflexive process, and used the regular multidisciplinary team discussions to ensure a balanced interpretation of the data. ${ }^{20}$

In order not to over-interpret the very small quantitative dataset from this pilot work, we have limited our presentation of data to graphical representation of the use of healthcare resources.

\section{Results \\ Participants}

Twenty-seven people from four general practices took part in the NHS Lothian pilot, all of whom agreed to provide data on their use of healthcare resources. The characteristics of the 27 patients in the pilot study and the 20 patients and 25 clinicians and managers who consented to participate in interviews or focus group discussions are given in Table 2. Installation was observed in three households and nine patients allowed observation of their use of the equipment.

\section{Overview of the qualitative data}

Despite some irritations with the technology, patients were generally very positive about the tele-monitoring service, highlighting earlier recognition of exacerbations, facilitation of access to professional advice, and the reassurance of being monitored as important benefits. Clinicians also felt that overall the service improved care, although they raised concerns about possible over-treatment of exacerbations, were aware of the increased workload, and expressed considerable frustration with aspects of the technology.

\section{Reducing delays in accessing care for exacerbations}

Patients consistently expressed anxieties about managing exacerbations, describing the difficulty of recognising the onset of an exacerbation, delays as they considered whether to seek professional advice, and the practical barriers to accessing professional care. Tele-monitoring was almost universally considered by both patients and their carers as helping to address these problems. The technology was perceived as being able to detect the early signs of an exacerbation (even before the patient realised he/she was ill) and, by providing a tangible symptom score, both validated the decision to seek help and ensured a prompt appointment.

"You'd think you would find it easy to tell when you're ill but it's only afterwards that you know you are not well. But this technology is really brilliant." [Female patient, 66 yrs, post-installation]

"I don't worry about him the same as I used to. It's all taken care of before it can get to that level. That machine can tell [him] he's ill even before he kens [knows] it himself." [Wife of patient, 75 yrs, post-installation]

"I think the machine does help you acknowledge that there's something. Whereas before you just say 'Och...' You just go into denial. It gives you something concrete." [Carer of a male patient, $67 \mathrm{yrs}$, post-installation]

"From that point of view, the machine's a great asset. It would throw up to somebody right away that you need attention. You're not getting blocked off by a receptionist." [Female patient, 69 yrs, pre-installation]

Completing the symptom scores was not always intuitive for patients who were constantly symptomatic. The questions asked if breathlessness or cough had increased, but some patients found it difficult to set a standard against which to benchmark their symptoms.

\section{"It asks 'Is it higher than normal?' I don't know what the} normal's supposed to be. So I don't know what ... Sometimes it's not all black and white." [Male patient, 69 yrs, post-installation]

Some patients appreciated the possibility of a remote consultation informed by the tele-monitoring data, thus avoiding the need to travel to the surgery.

"You know if something was wrong l'd get a phone call from the surgery ... they'd write a prescription and l'd get it sent to the chemist and then I'd get it delivered direct. Because if I'm unwell that's one thing I have to face is that 
Table 2. Characteristics of the participants

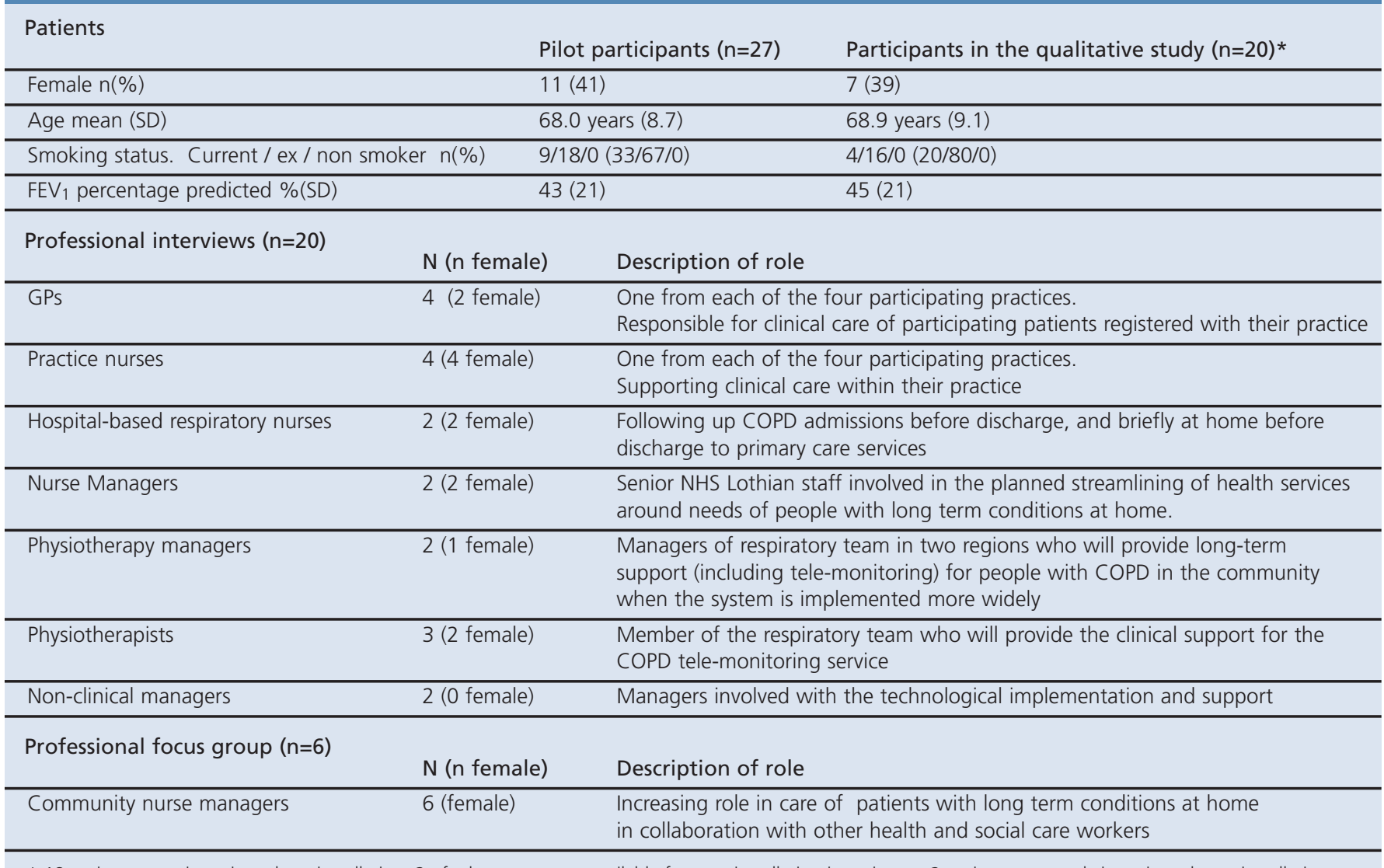

* 18 patients were interviewed pre-installation, 2 of whom were not available for post-installation interviews. 2 patients were only interviewed post-installation.

long walk to [the surgery], because there's no bus direct from here and, you know, when I'm unwell" [Female patient, 66 yrs, post-installation]

\section{Interpreting the incoming data}

In general the professionals' perception of benefits outweighed the initial rearrangement of work practices to accommodate the monitoring. Healthcare professionals were cognisant of the responsibility to ensure timely and competent monitoring of the incoming information.

"... there have to be good procedures in place for making sure that the information goes to whoever needs it ... without that you can have all the technology you like but it's not going to be useful." [Nurse Manager 1]

In contrast to the patients' perception of the advantages of having a score to inform objective decision-making, clinicians recognised the limitations of a standardised threshold and described the importance of interpreting the scores in context. Workload had increased as telephone calls or, occasionally, visits were made to clarify the reality of the individual clinical situation when the score breached the threshold.

"I thought it would be more clear-cut. It didn't occur to me it would be so difficult to work to a standard baseline. It's a lot more complex than I thought it was going to be." [GP 1]
"There's one lady that says 'No' [on the questionnaire] every day. But she's probably the worst patient on it. Her chest is terrible. I know she'll be struggling but she answers 'No'. She says 'I don't like to bother anyone'." [Practice Nurse 1]

\section{Recognising exacerbations or over-treatment?}

In keeping with the patients' assessment that the telemonitoring was sensitive to changes in their condition, clinicians initially assumed that the marked increase in prescriptions for antibiotics and steroids reflected improved recognition of exacerbations, although the possibility that the threshold for triggering an alert may have been set too low was raised. Later, the risks and benefits of what was perceived as a substantial increase in prescribing became a concern.

"But quite what effect all these antibiotics are going to have at the end of the line is a different story. It may be good if it keeps them out of hospital or if it makes them feel better generally, but I think ... these drugs are not without side effects." [GP 1]

Physiological measures were available to the clinicians, although their interpretation was not clear. Although oximetry was perceived as useful, lung function was considered to be unreliable and/or uninformative. 


\section{Empowering self-care or increasing dependence?}

There was an over-riding sense from patients and carers that the tele-monitoring system 'watched over' and 'looked after' them. Although some patients seemed to be describing an abrogation of personal responsibility as the technology could take over the decision about whether action was needed, most perceived that having access to readings and emergency supplies of antibiotics at home gave them confidence to respond to deteriorating symptoms themselves.

"In a way it was a relief thinking that I should ignore my own thoughts on getting a doctor or something like that. This organisation was going to get hold of a doctor if their readings showed I needed a doctor." [Female patient, 47 yrs, post-installation]

"It would be useful because if it happens at the weekends you're at the behest of NHS24 [a 24hour NHS telephone helpline] which is all very well, but they don't know the individual patients. If we had antibiotics or steroids, we could start them and then see on the Monday morning, you know, to assess what we had." [Carer for female patient, 87 yrs, post-installation]

One patient's experience flagged a potential risk as he assumed that the technology would monitor his heart condition as well as the COPD, and consequently delayed seeking help for his cardiac problem.

"You would have thought that they could have picked it up. With people of my age you would have thought that was one of the things they would have been looking for, you know, if someone has a low pulse rate." [Male patient, 78 yrs, post-installation]

\section{Usability and reliability of technology}

At the observation visits it was noted that the equipment generally integrated well into the home environment, although the size and background noise of the computer fan caused some problems in smaller more crowded living conditions. Most users quickly became familiar with the technology and found it easy to use. One particular worry was that the system failed to confirm that data had been transmitted, leaving patients uncertain whether the monitoring had been successful. None of the patients were concerned about confidentiality - if anything, they were worried that their data may not be shared widely enough.

Technical failures were a recurring concern, often the consequence of battery failure in one of the peripherals. A single responsive point of access to support was seen as important in ensuring issues were dealt with promptly. One patient withdrew as a result of a series of technical hitches which were not addressed quickly enough.

The design of the clinician interface was perceived as constraining rather than enhancing the task of monitoring, as it took little account of clinical requirements or the limited time available for monitoring.
Figure 4. Number of emergency prescriptions issued during the pilot study (2008) and to the same patients in the same 6- month period in 2007

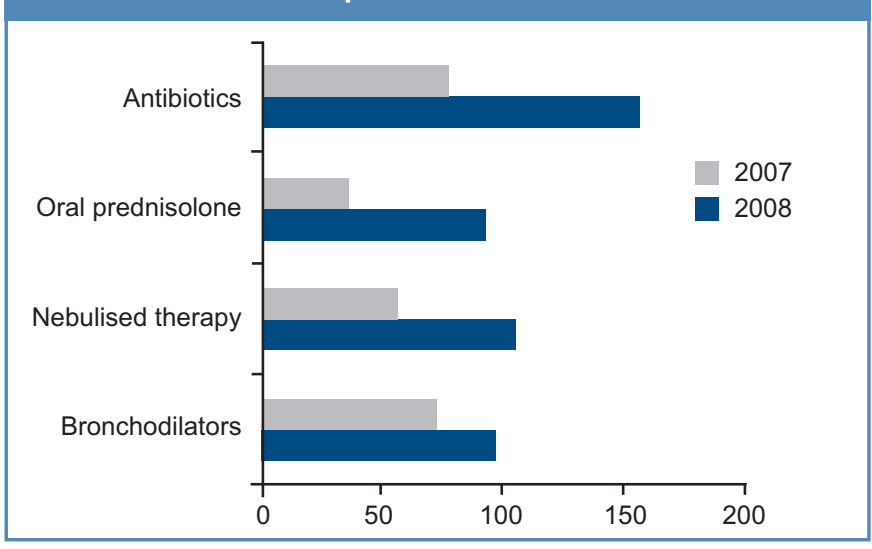

Figure 5. Number of primary care consultations for COPD during the pilot study (2008) and in the same 6-month period in 2007

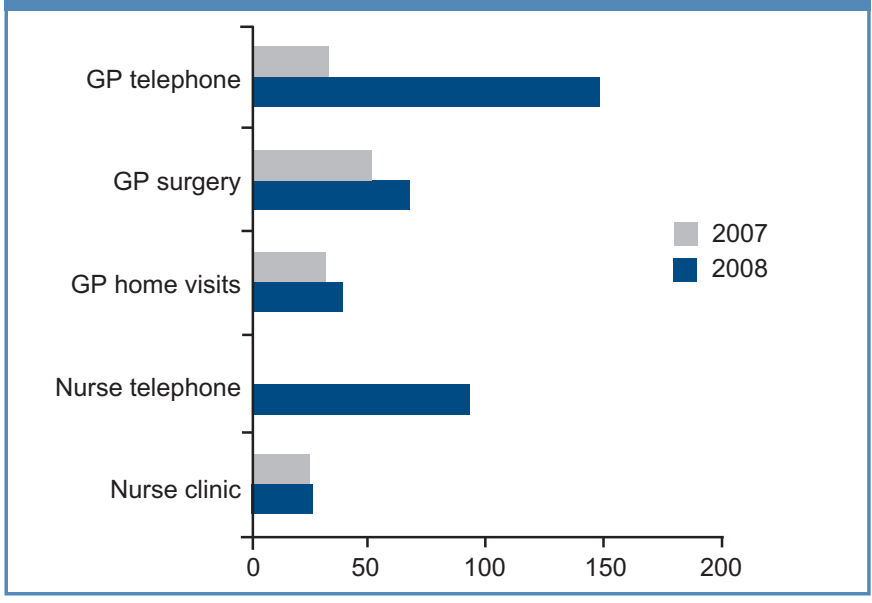

"I want to be able to see the information for ... my 20 patients and be able to glance at it and not ... I mean to look at one person's results must be - what eight different screens?" [GP2]

\section{Use of healthcare resources}

Figures 4-6 illustrate the use of healthcare resources at the two time points. Despite the small sample size, there was a marked and significant increase in prescribing for acute exacerbations (antibiotics, oral steroids, and nebulised medication) and a highly significant increase in primary care consultations (particularly telephone consultations). The data relating to secondary care usage were strongly skewed by one very long COPD admission (62 days) complicated by a stroke.

\section{Discussion}

\section{Summary of findings}

Patients were generally very positive about the technology. They were reassured by the idea that the system could not only detect impending exacerbations but provide objective evidence they 
Figure 6. Use of secondary care services for COPD during the pilot study (2008) and in the same 6-month period in 2007

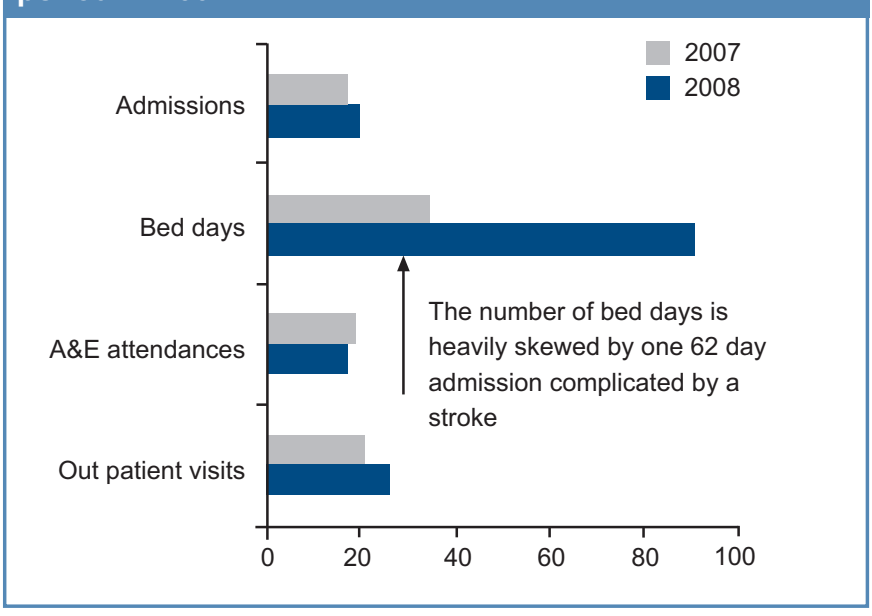

could use to confirm their decision to 'bother' their doctor and to overcome barriers to arranging a timely appointment. In contrast, clinicians balanced their perception of improved care with concerns about false positive symptom scores resulting in possible over-treatment, difficulties in interpreting physiological results, and an increased clinical workload.

The system proved feasible to implement, although highlighted the need for accessible technological support, and a number of practical suggestions were made for future iterations of the system. Workforce reorganisation to provide the necessary (trained) surveillance and clinical expertise was an issue for all the services involved - or intending to become involved as the tele-monitoring became mainstream.

\section{Limitations and strengths}

This was a pilot study. The numbers are small and caution should be exercised in interpreting the before-and-after quantitative data. Although we collected use of healthcare resources for the same time period in the preceding year to reduce the impact of seasonal fluctuations, other confounding factors may have influenced the results. For similar reasons we are unable to comment on the important issue of cost-effectiveness of telemonitoring for COPD.

The majority of the patients in the pilot participated in the qualitative evaluation and their characteristics were similar to those who declined interviews. The participating practices were likely to be positive about the benefits of technology, which may have influenced how they approached the task of monitoring and their perceptions of the advantages and disadvantages of the service.

\section{Interpretation of findings in relation to previously published work}

Our findings support the concept that tele-monitoring operates at the boundary between professional and self-care (see Figure 1), ${ }^{10}$ and introducing the tele-monitoring system impacted on all aspects of this model.
The core function of the technology is to support communication across the boundary, and patients generally felt that it facilitated access both in terms of negotiating a timely appointment with reception staff and also enabling remote consultations. At a technical level this generally operated well, although our pilot experience raised some important concerns (such as the lack of confirmation of data transmission and the unfriendly professional interface) which potentially compromised communication.

The difficulty that patients with COPD have in differentiating between the onset of an exacerbation and a self-limiting 'bad day' is well recognised, ${ }^{21,22}$ as are the practical barriers to achieving a timely appointment. ${ }^{23}$ The patients in our study described similar anxieties when deciding to 'cross the boundary' and seek professional help. The perception that the monitoring provided an objective measure which could distinguish those symptoms which needed clinical attention was thus widely welcomed by the patients and their carers, who felt it both allowed and enabled them to seek professional help. For professionals the situation was more complex. Aware that early treatment of exacerbations improves outcomes, ${ }^{17}$ clinicians initially welcomed the increased recognition of exacerbations, but realisation of a consequent increase in prescribing of steroids and antibiotics (reflected in our quantitative data) led to increasing concerns about over-treatment and side effects. Our ongoing RCT will quantify this observation and demonstrate whether the increased prescribing reduces hospitalisations for COPD and/or improves quality of life, ${ }^{19}$ but the concern about long-term risk/benefits of this strategy will require further research. The need for more clinical information to aid interpretation of the objective measures resulted in frequent telephone consultations to clarify the situation.

The importance of the underpinning clinical services on the effectiveness of tele-monitoring is well recognised, ${ }^{14}$ and the professionals whom we interviewed were actively discussing service reorganisation to support the roll-out of tele-monitoring throughout NHS Lothian. For a condition subject to unpredictable exacerbations, computer facilities and trained professional time have to be available on a daily basis. Whilst service models may vary, an important consideration is the advantage of the clinicians knowing the patient, their clinical background and 'usual' scores in order to interpret incoming monitoring data.

Concerns have been expressed that tele-monitoring might engender dependence rather than empower self-care, ${ }^{24}$ and statements such as "I've never felt so well looked after in my life" might be seen as reinforcing that interpretation. However, it was also clear that monitoring empowered patients to take responsibility by giving them objective information on which to base decisions about commencing emergency courses of steroids and antibiotics. Concerns have been expressed, however, that tele-health promotes compliance with clinical models of care rather than true collaborative self-management. ${ }^{25}$ 


\section{Conclusions and implications}

Introducing tele-monitoring for COPD has far-reaching implications for clinical care and service development. The system we piloted was perceived by patients as improving access to professional care, but highlighted the difficulty for clinicians of interpreting data without a clinical assessment and raised concerns about possible over-treatment. Whilst our ongoing RCT will provide information about the clinical effectiveness and costeffectiveness of tele-monitoring in reducing admissions, questions will remain about how best to organise systems to support the technology.

\section{Handling editor Chris Griffiths}

Acknowledgements We would like to thank the participating patients and general practices, Careline who provided the monitoring, the Wellcome Clinical Research Facility nurses who undertook the data collection, Paddy Corscadden and the NHS Lothian IT team who implemented the technology. We acknowledge the support of the TELESCOT Independent Trial Steering Committee, Professor Lewis Ritchie (chairman), Professor Chris Griffiths, and Professor Anne-Louise Kinmonth. Conflicts of interest Although supported by Intel and Tunstall, neither organisation had influence on the design, conduct or reporting of the study. AS is a consultant to ALK and Phadia. He has advised the Scottish Government and House of Lords Allergy Inquiry. He is the Royal College of General Practitioners Clinical Champion in Allergy. AS is the Joint Editor-in-Chief of the PCRJ, but was not involved in the editorial review of, nor the decision to publish, this article.

ContributorshipThe project was designed by $B M, H P, J H, C P, A S, W P$. Interviews were carried out by JU, AT and GK; analysis of the qualitative work was carried out by JU and GK with input from the wider team. EM carried out the quantitative analysis. The paper was written mainly by JU and HP with input from the wider team.

Funding This study was funded by a grant from Intel and Tunstall and was supported by the Scottish Centre for Telehealth. HP and BMcK were in receipt of Senior Clinical Fellowships from the Chief Scientist Office of the Scottish Government during the course of the project. All equipment was supplied by NHS Lothian. AT was funded by Intel for evaluation of the Lothian COPD Telehealth Study.

\section{References}

1. Wanless D. Securing our Future Health: Taking a Long-Term View. London: HM Treasury, 2002.

2. Department of Health. Our Health, Our Care, Our Say: A New Direction for Community Services. London: The Stationery Office, 2006.

3. Scottish Executive Health Department. A National Framework for Service Change in the NHS in Scotland. Building a Health Service Fit for the Future. Edinburgh: Scottish Executive, 2005.

4. Department of Health. The Expert Patient: A New Approach to Chronic Disease Management for the 21st Century. London: Department of Health, 2001.

5. Scottish Executive Health Department. Delivering for Health. Edinburgh: Scottish Executive, 2005.

6. Department of Health. Improving Chronic Disease Management. London: The Stationery Office, 2004.
7. Department of Health. Information for Health: an Information Strategy for the Modern NHS 1998-2005. London: Department of Health, 1998.

8. Institute of Medicine. Crossing the Quality Chasm. A ew Health System for the 21st Century. Washington: National Academy Press, 2001.

9. Glasziou P, Irwig L, Mant D. Monitoring in chronic disease: a rational approach. BMJ 2005;330:644-8. http://dx.doi.org/10.1136/bmj.330.7492.644

10. Kielmann T, Huby G, Powell A, et al. From support to boundary: a qualitative study of the border between self care and professional care. Patient Educ Counsel 2010;79:55-61. http://dx.doi.org/10.1016/j.pec.2009.07.015

11. McKinstry B, Pinnock $H$, Sheikh A. Telemedicine for management of patients with COPD? Lancet 2009;374:672-3. http://dx.doi.org/10.1016/50140-6736(09)61542-7

12. Dale J, Connor $S$, Tolley K. An evaluation of the West Surrey telemedicine monitoring project. Telemed and Telecare 2003;9:39-41. http://dx.doi.org/ 10.1258/135763303322196295

13. Trappenburg JC, Niesink A, de Weert-van Oene GH, et al. Effects of telemonitoring in patients with chronic obstructive pulmonary disease. Telemed J E-Health 2008;14:138-46. http://dx.doi.org/10.1089/tmj.2007.0037

14. Casas A, Troosters T, Garcia-Aymerich J, et al. Integrated care prevents hospitalisations for exacerbations in COPD patients. Eur Respir J 2006;28:1-8. http://dx.doi.org/10.1183/09031936.06.00063205

15. Pinnock $H$, Thomas $M$, Tsiligianni I, et al. The International Primary Care Respiratory Group (IPCRG) Research Needs Statement 2010. Prim Care Respir J 2010;19(Suppl 1): S1-S21. http://dx.doi.org/10.4104/pcrj.2010.00021

16. The TELESCOT programme. Investigating telemetric supported self monitoring of long term health conditions. http://www.telescot.org (accessed October 2010).

17. Seemungal TAR, Donaldson GC, Bhowmik A, Jeffries DJ, Wedzicha JA. Time course and recovery of exacerbations in patients with chronic obstructive pulmonary disease. Am J Respir Crit Care Med 2000;161:1608-13.

18. Craig P, Dieppe P, Macintyre S, Mitchie S, Nazareth I, Petticrew M. Developing and Evaluating Complex Interventions: New Guidance. London: Medical Research Council, 2008.

19. Pinnock $\mathrm{H}$, Hanley J, Lewis $\mathrm{S}$, et al. The impact of a telemetric chronic obstructive pulmonary disease monitoring service: randomised controlled trial with economic evaluation and nested qualitative study. Prim Care Respir J 2009;18:233-5. http://dx.doi.org/10.4104/pcri.2009.00040

20. Cutcliffe JR. Reconsidering reflexivity: introducing the case for intellectual entrepreneurship. Qual Health Res 2003;13:136-48. http://dx.doi.org/ 10.1177/1049732302239416

21. Adams R, Chavannes N, Jones K, Stubbe-Ostergaard M, Price D. Exacerbations of chronic obstructive pulmonary disease - a patients' perspective. Prim Care Respir J 2006;15:102-09. http://dx.doi.org/10.1016/j.pcri.2006.01.003

22. Jones P, Harding G, Wiklund I, Berry P, Leidy N. Improving the process and outcome of care in COPD: development of a standardised assessment tool. Prim Care Respir J 2009;18:208-15. http://dx.doi.org/10.4104/pcrj.2009.00053

23. Shipman C, White S, White P. Access to services in advanced COPD: factors that influence contact with general practice services. Prim Care Respir J 2009; 18:2738. http://dx.doi.org/10.4104/pcrj.2009.00013

24. Pinnock H, Slack R, Pagliari C, Price D, Sheikh A. Understanding the potential role of mobile phone based monitoring on asthma self-management: qualitative study. Clin Exp Allergy 2007;3:794-802. http://dx.doi.org/10.1111/j.1365-2222.2007.02708.x

25. Schermer $M$. Telecare and self-management: opportunity to change the paradigm. J Med Ethics 2009;35:688-91. http://dx.doi.org/10.1136/jme.2009.030973

Available online at http://www.thepcrj.org 
Appendix 1: Topic guide

\section{Patient Discussion Topics}

Interview 1. Pre-installation of System

\begin{tabular}{|c|c|}
\hline Topic & Explore \\
\hline Experience of the illness & $\begin{array}{l}\text {-impact on lifestyle } \\
\text {-coping strategies }\end{array}$ \\
\hline Involvement in project & $\begin{array}{l}\text {-experience of recruitment } \\
\text {-reason for participation }\end{array}$ \\
\hline Recruitment process & $\begin{array}{l}\text {-how they got involved } \\
\text {-why they agreed to participate } \\
\text {-perception of purpose of the pilot }\end{array}$ \\
\hline Exacerbations & $\begin{array}{l}\text {-delays in seeking / getting help } \\
\text {-reasons for this }\end{array}$ \\
\hline Support issues & $\begin{array}{l}\text {-from family } \\
\text {-from professionals }\end{array}$ \\
\hline Confidentiality & -any concerns about data being shared across wider team \\
\hline Expected benefits & $\begin{array}{l}\text {-in terms of care } \\
\text {-in terms of how they feel } \\
\text {-in terms of how they manage the condition } \\
\text {-in terms of outcomes }\end{array}$ \\
\hline Anticipated concerns & $\begin{array}{l}\text {-using equipment/IT } \\
\text {-cost } \\
\text {-space/location }\end{array}$ \\
\hline $\begin{array}{l}\text { Communication with health } \\
\text { professionals (how often/face to } \\
\text { face/phone/video) }\end{array}$ & $\begin{array}{l}\text {-doctors } \\
\text {-nurses } \\
\text {-other professionals }\end{array}$ \\
\hline
\end{tabular}

Interview 2. System in Use

\begin{tabular}{|c|c|}
\hline Topic & Explore \\
\hline Installation of the telecare equipment & $\begin{array}{l}\text {-location } \\
\text {-impact / restrictions on other home activities } \\
\text {-costs } \\
\text {-space } \\
\text {-visual impact }\end{array}$ \\
\hline Experience of training & $\begin{array}{l}\text {-ease of understanding } \\
\text {-length }\end{array}$ \\
\hline Usability of the technical system & $\begin{array}{l}\text {-technical usability (interface/ peak flow/pulse } \\
\text { oximetry/online Qs } \\
\text {-need for support help from others } \\
\text { (carer/GP/helpline/other) } \\
\text {-timing of sessions } \\
\text {-impact on domestic routines (fan/alarm/room use/phone } \\
\text { use) } \\
\text {-what could be added/changed to improve } \\
\text { acceptability/usability }\end{array}$ \\
\hline Usability of the process & $\begin{array}{l}\text {-interventions triggered by the system } \\
\text {-perceptions of this experience (what worked, what didn't) } \\
\text {-impact on how they /others now manage their care }\end{array}$ \\
\hline $\begin{array}{l}\text { Experience of managing illness with } \\
\text { tele-monitoring }\end{array}$ & $\begin{array}{l}\text {-daily routine using the system } \\
\text {-how they feel about managing symptoms this way }\end{array}$ \\
\hline
\end{tabular}


Appendix 1: Topic guide continued

\begin{tabular}{|c|c|}
\hline & $\begin{array}{l}\text {-impact on ability to recognise /act on symptoms } \\
\text {-impact on care } \\
\text {-impact on domestic routine }\end{array}$ \\
\hline Perceptions of others & $\begin{array}{l}\text {-carer } \\
\text {-other family members } \\
\text {-visiting care professionals }\end{array}$ \\
\hline Perceived benefits in terms of & $\begin{array}{l}\text {-care (access to /quality of) } \\
\text {-management the condition (by care team/ self care) } \\
\text {-identifying symptoms } \\
\text {-how they feel } \\
\text {-other }\end{array}$ \\
\hline Perceived problems / concerns & $\begin{array}{l}\text {-usability of process } \\
\text {-usability of equipment/IT } \\
\text {-support with technical problems } \\
\text {-costs (e.g- phone or electricity bills) } \\
\text {-location } \\
\text {-disruption to domestic activities (fan/alarm/room use } \\
\text { /phone use) } \\
\text {-other }\end{array}$ \\
\hline Confidentiality & -concerns about sharing information across wider team \\
\hline $\begin{array}{l}\text { Communication with health } \\
\text { professionals (how often/face to } \\
\text { face/phone/video) }\end{array}$ & $\begin{array}{l}\text {-doctors } \\
\text {-nurses } \\
\text {-other professionals }\end{array}$ \\
\hline Recommended changes & $\begin{array}{l}\text {-to technical system } \\
\text {-to process } \\
\text {-to recruitment/installation and training } \\
\text {-other }\end{array}$ \\
\hline
\end{tabular}

N.B. Some of the sub-topics in the second interviews follow up/expand on specific issues and concerns that emerged from open questions in the pre-interviews with the same patients.

\section{Professional Discussion Topics}

\begin{tabular}{|c|c|}
\hline Topic & Explore \\
\hline Can I ask what your role normally is? & $\begin{array}{l}\text { - normally } \\
\text { - on the pilot project }\end{array}$ \\
\hline $\begin{array}{l}\text { I'd like to know what your } \\
\text { expectations (or experiences) are for } \\
\text { use of the Personal Health System } \\
\text { with COPD patients at home? }\end{array}$ & $\begin{array}{l}\text { - for supporting care } \\
\text { - for particular groups } \\
\text { - for supporting self-care } \\
\text { - in relation to exacerbations / hospital admissions } \\
\text { - for healthcare providers (NHS/Social Care) }\end{array}$ \\
\hline $\begin{array}{l}\text { Do you see any particular benefits to } \\
\text { this approach? }\end{array}$ & $\begin{array}{l}\text { - In relation to COPD exacerbations } \\
\text { - In relation to care } \\
\text { - In relation to self care }\end{array}$ \\
\hline Do you have any particular concerns? & $\begin{array}{l}\text { - Usability } \\
\text { - Patient: doctor : care communication } \\
\text { - Patient perceptions of disease } \\
\text { - New roles responsibilities } \\
\text { - Tension between research, training, clinical care aims } \\
\text { - Interpretation of results - representativeness, variation, } \\
\text { validity }\end{array}$ \\
\hline
\end{tabular}


Appendix 1: Topic guide continued

\begin{tabular}{|c|c|}
\hline & $\begin{array}{l}\text { - Workload } \\
\text { - Use of protocols } \\
\text { - Use of IT in the home -which scenarios - which groups } \\
\text { - Training Issues - respiratory nurses, use of equipment } \\
\text { etc. } \\
\text { - Privacy Issues (legal?) } \\
\text { - Support and maintenance? Identification and follow-up } \\
\text { on technical issues } \\
\text { - Use with different groups? }\end{array}$ \\
\hline $\begin{array}{l}\text { What has been your experience of the } \\
\text { roll out of the project to date? } \\
\text { In particular, facilitotors or barriers } \\
\text { for wider pilot }\end{array}$ & $\begin{array}{l}\text { - Readiness } \\
\text { - Technology } \\
\text { - Process, protocols } \\
\text { - Impact on working practices } \\
\text { - Recruitment } \\
\text { - Coordination of processes } \\
\text { - Communication? } \\
\text { - Consultation? } \\
\text { - Training } \\
\text { - Timing }\end{array}$ \\
\hline $\begin{array}{l}\text { What would your key personal criteria } \\
\text { for a successful project be? }\end{array}$ & - Why? \\
\hline \multicolumn{2}{|c|}{ (Q6-9) are only relevant if familiar with the system or this can be demonstrated } \\
\hline \multicolumn{2}{|l|}{$\begin{array}{l}\text { What are your perceptions of the } \\
\text { patient interface at this stage? }\end{array}$} \\
\hline \multicolumn{2}{|l|}{$\begin{array}{l}\text { What are your perceptions of the } \\
\text { web-based interface at this stage? }\end{array}$} \\
\hline \multicolumn{2}{|l|}{$\begin{array}{l}\text { What are your perceptions of the } \\
\text { current protocol for communication } \\
\text { between patient, call centre and GP } \\
\text { at this stage? }\end{array}$} \\
\hline $\begin{array}{l}\text { What are your perceptions of the } \\
\text { digital peripherals }\end{array}$ & $\begin{array}{l}\text { - FEV1 monitor } \\
\text { - Oxygen saturation monitor } \\
\text { - Patient symptom self-report questionnaire }\end{array}$ \\
\hline $\begin{array}{l}\text { Is there anything else you would like } \\
\text { to add? }\end{array}$ & \\
\hline
\end{tabular}




\section{COPD pilot: coding framework}

\section{PATIENT PERSPECTIVES}

\section{Benefits anticipated}

Reduction of delay in diagnosis and intervention due to

Delay where worried about wanting to bother the doctor /

Difficulty getting an appointment

Difficulty identifying exacerbations

Inaction where patients see no point in seeking help.

Good coping strategies/ high tolerance levels that mask need for help

Wait and see approach when symptoms get worse or better rapidly

Lack of unambiguous/tangible evidence for patients to feel justified calling a GP

Delays in getting prescription and antibiotics

Fear of unwanted consequences (emergency hospital admission; side effects of steroids)

Delays due to walking distance or lack of transport to surgery and chemist

\section{Benefits experienced}

\section{Reduction of delay in diagnosis and intervention}

Earlier access to appointments via triage

Earlier contact with surgery as a result of own/carer's acknowledgement of problem

Earlier access to prescription / appointment for prescription

Use of readings as justification/evidence for calling GP earlier

Earlier response to early signs of exacerbation (by doctors, careline or patients)

\section{Delays experienced}

Potential delay because someone else is seen as having responsibility for monitoring (ipatient may abdicate responsibility - perception from comments that this might happen)

Potential delay where technology or communication breaks down (one case)

\section{Greater awareness of symptoms and condition reinforce}

-earlier and more appropriate intervention by patient or carer 


\section{- behaviour change}

Helps reinforce improvements with lifestyle changes

Doctors /practices are better informed

Increased awareness of condition for some patients, not for others (roughly 50:50)

GP/nurses perceived as more aware of their condition

Knock on benefits through reviews of treatment or equipment

Perceived prevention of admissions by some patients and carers

General comments on perceived benefit (non-specific comments)

\section{Reduction in anxiety and greater reassurance for patients (and carers)}

Less anxiety about delays in intervention

Less anxious about getting an appointment

Less anxiety in deciding if they should phone or not

Greater sense of safety, security or reassurance being monitored

(need to unpick WHAT they think they are being monitored for, and WHEN)

\section{PROFESSIONAL PERSPECTIVES}

\section{View of telehealth}

Prevention of exacerbation is based on clinical support and IT is just the medium

\section{Perceived needs}

Effective communication of patient Information to distributed team

Effective communication across CHPs

Effective communication across distributed teams

Effective communication across patient records systems

Reliable IT infrastructure

Reliable IT

Reliable IT support both centrally and locally

Reliable Process

Ease of Use for Patients and Practitioners

Coordination of knowledge, expertise and services for LTCs 
Appendix 2: Coding framework continued

Not clear how this will all fit together

Needs to be aligned with the Nursing Review

Making partnerships with other specialists

\section{Perceived benefits}

Early warning system

Reassurance for patients and carers

Support for patients reluctant to bother a GP

\section{Perceived opportunities}

Web-based access to patient data by different teams

Potential to share more recent/relevant information from different sources

Potential to reinforce self care skills with video

Vehicle for extending/coordinating work of different care teams

Basis for prioritising visits

Basis for extending services to hard to reach patients

$\underline{\text { Support for prioritising visits }}$

\section{Concerns}

Validity of measures and threshold scores in decision-making

Impact of other (contextual/patient specific) factors on scores (anxiety, underscoring etc)

Impact of usability on scores

Impact of individual variation/ need for individual thresholds

Are we measuring the right things?

Coping strategies can mask deterioration

Self report questions do not differentiate

Impact on Roles and Workload

Could be overstretched and under-resources

Manageable after initial reconfiguration

Lack of specialist training

Lack of face to face exchanges

Lack of visual cues that help in face to face diagnosis 
Appendix 2: Coding framework continued

Concerns about compliance with changes in medication

\section{DATA MANAGEMENT ISSUES}

\section{Delays, gaps in triage}

Technical breakdown issues (batteries, server virus, monitoring delay can be $24 \mathrm{hrs}$

Communication delays between system, call centre, doctor and patient

Issues of what to do in case of technical problems or symptoms that don't trigger a call

Careline were good at following up missing readings or gaps in service

Communication with careline about holidays/appointments was poor - no protocol

System interface unhelpful during transmissions/technical failures

\section{Protocol / threshold scores in triage: one size does not fit all}

Threshold too low for some

Interpreting Scores requires knowledge of patient and context (from nurse and patient)

Different scenarios evolved, which only suited some groups

- triage with a protocol was a poor indicator

- triage refined by a second stage involving telephone or videoconference with patient was a good compromise but work and time intensive

- triage by asking patients to phone GP on basis of own readings split opinions, with around half feeling this was more efficient, and half feeling very anxious that they would revert to their original situation, where they were (a) unsure when to phone (b) unwilling to bother doctor and (c) anxious that they would not get an appointment in time resulting in a panic attack or a hospital admission.

- Readings as evidence / justification of need (having 'permission to call')

System for many seen as as a proxy for accessing services seen as difficult to get.

Confusion by some patients as to what was being monitored (ie not just COPD)

Patient concerns with nurse/surgery workloads as a result of additional calls

Importance of trust in surgery to respond rapidly and well

\section{TECHNICAL / USABILITY ISSUES}

\section{Failure to transmit / transmit properly/ be seen to tranmit}

Not clear if has transmitted (See also battery failure)

4 
Appendix 2: Coding framework continued

Concerns about risks of transmission failure

Responsiveness of GP and Careline to failed transmissions

Pulse Oximetry / Battery (often reported as failure to connect or transmit)

Low battery - risk this is impacting on readings

Batteries fitted differently from normal

Impact of low batteries on pulse oximetry readings

Blank screen

Impact of moving finger on pulse oximetry readings

Virus on server

\section{Impact of unexplained / unexpected system failure}

Not knowing why things failed

Stress and inconvenience of unexpected or unexplained failure (See also delays in triage)

Number to call in case of failure

Connectivity (although usually this means battery failure!)

Fear of messing around with computer (to see readings, videos etc.)

Security/Confidentiality Not an issue raised by anyone this time round

\section{Usability of system in general}

Getting the hang of it often required partner/carer

Fine (almost unilateral initial response)

More difficult for older, deaf or short sighted patients

Part of the daily routine

Anxiety about ability to use IT (typical of female patients)

\section{Role of carers in supporting use / usability}

Sequence too complex for some without support (role of carer)

Need to scope this in allocating system

\section{Usability of different parts of the system}

\section{1. $\mathrm{FEV}_{1}$}

Difficult to get a reading

Didn't always transmit

Difficult sequence that is time sensitive

Buttons too small

Beeps too quiet 
Appendix 2: Coding framework continued

Stress of constant breakdowns

Inconvenience where position of points constrains use of rooms or other equipment

Table not always available for comfortable use (Lothian Stores can provide)

\section{Online symptom questionnaire}

Perceived as Ambiguous and unclear / Too black and white

Perceived and also identified as Subject to under or over-scoring (N)

Benchmark Questionnaire described as too long , irrelevant, repetitious, patronising

\section{Videos}

Useful information about condition

Seen by some as opportunity to provide additional services / eg pulm rehab. booklets

\section{Front end and navigation}

Seen as straightforward

5. Web cam

Need for a second layer over and above threshold scores

Yes No Maybe

6. Alarm

Alarm as stressful or disruptive for over half

Alarm a good thing as a reminder for less than half

Indifferent or get used to it after initial period

\section{INSTALLATION /TRAINING/IT SUPPORT}

\section{Installation}

Constrained use of room or use of other equipment

Fan noise initial issue

Fear of possible costs (Small group but persistent concern)

Concerns that it is always plugged in (as above)

Confidentiality is still NOT a concern

\section{Training}

Fine/ OK (majority)

Need more support (minority esp women)

6 
Appendix 2: Coding framework continued

Role of carer as training back up

\section{IT Support}

Seen as responsive and personal

\section{MANAGEMENT OF ILLNESS / SELF CARE}

Management of illness seen as difficult as symptoms are seen as ambiguous, services often difficult to access, and outcomes may not be those preferred

Perceptions of system as potentially very useful by other care professionals who need ot prioritise or extend services within time and budget constraints

Perceptions of value of physiotherapy - could some information be on the system (feedback from small group newly involved in Pulmon.. Rehab. plus one of GPs) 